\title{
Case Study of a 15-Year-old Boy with McCune-Albright Syndrome Combined with Pituitary Gigantism: Effect of Octreotide-long Acting Release (LAR) and Cabergoline Therapy
}

\author{
TOSHIHIRO TAJIMA, JUNKO TSUBAKI, KATSURA ISHIZU, WAKAKO JO, NOBUAKI ISHI* \\ AND KENJI FUJIEDA** \\ Department of Pediatrics, Hokkaido University School of Medicine, N15, W7, Sapporo, Japan 060-0835 \\ *Department of Neurosurgery, Hokkaido University School of Medicine, N15, W7, Sapporo, Japan 060-0835 \\ **Department of Pediatrics, Asahikawa Medical College 2-1-1-1, Midorigaoka, Higashi, Asahikawa, 078-8510, Japan
}

\begin{abstract}
The use of octreotide-LAR and cabergoline therapy has shown great promise in adults with acromegaly; however, the experience in pediatric patients has rarely been reported. We described a clinical course of a 15-year-old boy of McCune-Albright syndrome (MAS) with pituitary gigantism. At the age of 8 years, a growth hormone (GH) and prolactin (PRL) producing pituitary adenoma was diagnosed at our hospital. He also had multiple fibrous dysplasia, so that he was diagnosed as having MAS. The tumor was partially resected, and GNAS1 gene mutation (R201C) was identified in affected tissues. We introduced octreotide to suppress GH secretion $(100 \mu \mathrm{g} \times 2 /$ day s.c $)$. During therapy with octreotide, IGF-1 and GH levels could not be suppressed and the patient frequently complained of nausea from octreotide treatment. Therefore, the therapy was changed to monthly injections of octreotide-LAR at the age of 12.3 years and was partially effective. However, as defect of left visual field worsened due to progressive left optic canal stenosis, he underwent second neurological decompression of the left optic nerve at 13.4 years of age. After surgery, in addition to octreotide-LAR, cabergoline ( $0.25 \mathrm{mg}$ twice a month) was started. This regimen normalized serum levels of GH and IGF1; however, he showed impaired glucose tolerance and gallstones at 15.7 years of age. Therefore, the dose of octreotideLAR was reduced to $10 \mathrm{mg}$ and the dose of cabergoline increased. This case demonstrated the difficulty of treating pituitary gigantism due to MAS. The use of octreotide-LAR and cabergoline should be considered even in pediatric patients; however, adverse events due to octreotide-LAR must be carefully examined.
\end{abstract}

Key words: McCune-Albright syndrome (MAS), Pituitary gigantism, Fibrous dysplasia, Octreotide-LAR, Cabergoline

(Endocrine Journal 55: 595-599, 2008)

MCCUNE-ALBRIGHT syndrome (MAS) is a sporadic disease characterized by precocious puberty (mostly in girls), polyostotic fibrous dysplasia and café-au-lait pigmented skin lesions as the classical main features $[1,2]$. MAS patients may also present with a number of other endocrine abnormalities which include hyperfunctional thyroid nodules, macronodular

Received: September 5, 2007

Accepted: March 9, 2008

Correspondence to: Toshihiro TAJIMA, M.D., Ph.D., Department of Pediatrics, Hokkaido University School of Medicine, N15, W7, Sapporo 060-8638, Japan adrenal hyperplasia or adrenal adenomas, pituitary tumors leading to acromegaly and/or hyperprolactinemia, and hypophoshatemic rickets or osteomalacia [14]. The underlying molecular mechanism of MAS is a postzygotic activating mutation of the GNAS gene that encodes for the $\alpha$-subunit of the stimulatory heterotrimeric G protein complex Gs $\alpha[1,2]$.

Recent reports demonstrated that $\mathrm{GH}$ excess is present in approximately $20 \%$ of the patients with MAS $[5,6]$. Furthermore, GH excess in MAS is a risk factor for loss of vision and hearing due to expansion of fibrous dysplasia of craniofacial bone $[5,7,8]$. Medical therapy has been done to treat GH excess in MAS; 


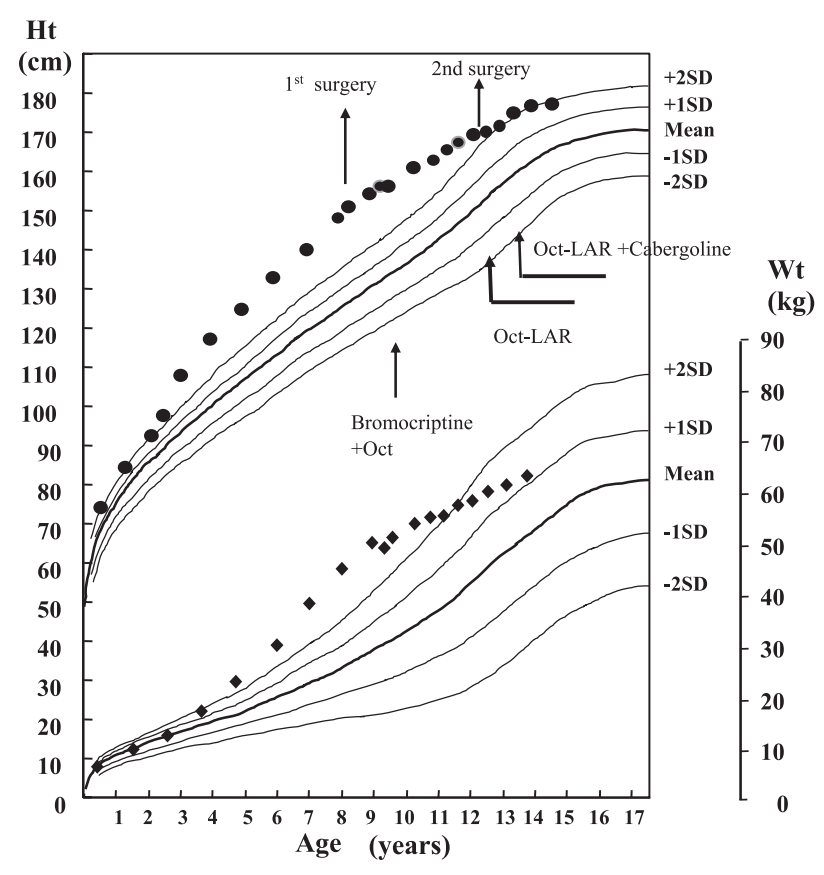

Fig. 1. Growth curve of a 15-year-old boy with pituitary gigantism of MAS. Oct, octreotide

however, the effects are limited [9-12].

Here we reported a 15-year-boy with MAS and pituitary gigantism treated by octreotide-LAR and cabergoline.

\section{Case Report}

A 4-yr-old boy visited an orthopedist with a spontaneous fracture of his left femoral bone. He underwent femoral stapling and bone transplantation. Six months later, facial asymmetry and a prominence of superciliary arch were pointed out; however, no further medical attention was paid to the condition. At the age of 8 years, he visited a neurosurgery clinic with worsening headaches and nausea. Cranial magnetic resonance imaging (MRI) revealed a pituitary macroadenoma. He was thus presented to us for endocrinological evaluation. When first seen, his body height was $151.0 \mathrm{~cm}$ (SD score, +4.7 for normal Japanese boy). His rapid linear growth from 3 years of age was observed (Fig. 1). His bone age was not accelerated, and signs of precocious puberty were not found (testicular volume, $2 \mathrm{ml}$ ). No café-au-lait spots were found. He had an asymmetrical face and a prominent superciliary arch. Ophthalmologic evaluation revealed defect of left visu-

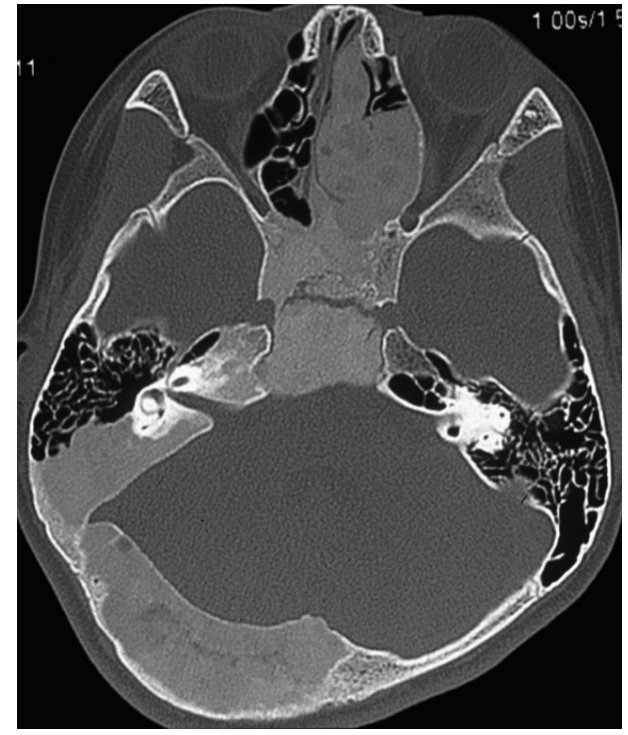

Fig. 2. Horizontal CT scan reveals massive lesions of polyostotic fibrous dysplasia displacing the ethmoid sinus, sphenoid sinus, and mastoid antrum.

al field and dilated Mariotte blind spot on the left side. Neurological examination was normal. Serum IGF-I and IGFBP-3 levels were extremely high $(1160 \mathrm{ng} / \mathrm{ml}$ $(50-356 \mathrm{ng} / \mathrm{ml},-1.96 \mathrm{SD} \pm 1.96 \mathrm{SD}$ for normal Japanese boy between $7-9$ years old)), and $4.60 \mathrm{ng} / \mathrm{ml}$ $(1.75-4.04 \mathrm{ng} / \mathrm{ml},-1.96 \mathrm{SD} \pm 1.96 \mathrm{SD}$, respectively). Basal GH was $73.7 \mathrm{ng} / \mathrm{ml}$ and PRL, $249 \mathrm{ng} / \mathrm{ml}$. GH was not suppressed by oral glucose tolerance test, and paradoxically increased by TRH stimulation. A CT scan revealed massive cranial osseous lesions that displaced the ethmoid sinus, sphenoid sinus and mastoid antrums (Fig. 2). An MRI scan showed a pituitary tumor with its infiltration into cavernous sinus and a thick osseous clival lesion displacing the pituitary upward (Fig. 3). He was diagnosed as having MAS and $\mathrm{GH}$ excess by these findings. Because transsphenoidal surgery was impossible, he underwent transfrontal surgery and approximately two thirds of the adenoma was removed. The tumor tissue stained positive to GH and PRL immunoreactivity. At the same time, thick skull lesions of fibrous dysplasia were partially resected and left optic canal was unroofed. The pre-operational defect of visual field on the left side was soon recovered. In the patient's tumor tissues the activating mutation of R201C of the GNAS gene was identified. Therapy with bromocriptine and octreotide with subcutaneous daily injections was started. As shown in the Table 1, this therapy successfully suppressed PRL secretion, but 


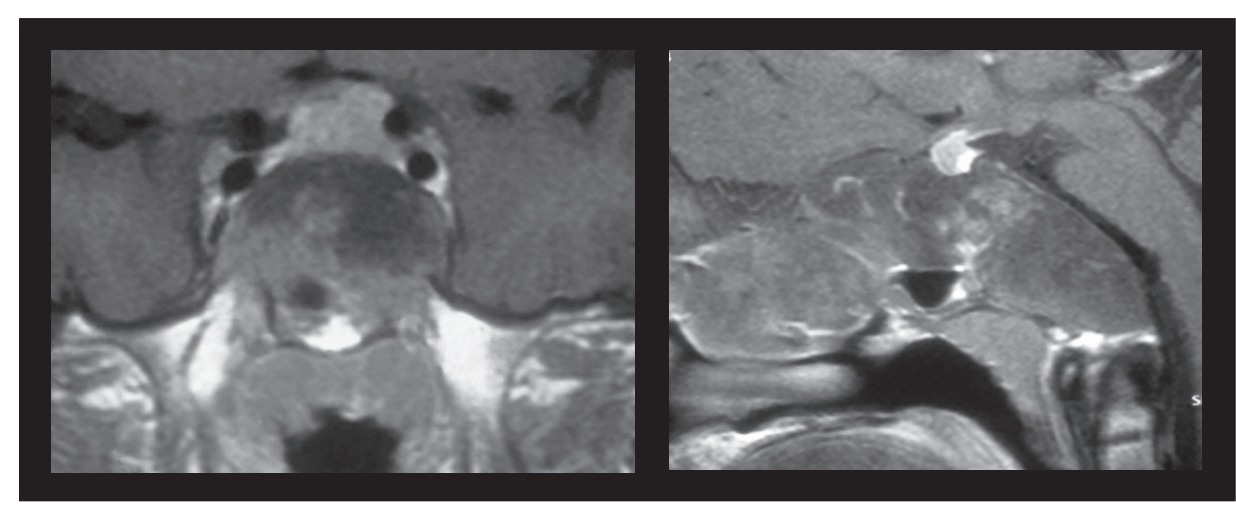

(A)

(B)

Fig. 3. Coronal (left) and sagittal (right) T1-weighted magnetic resonance images, enhanced with Gd-DTPA. Massive lesions of fibrous dysplasia displace pituitary tissue (including adenoma) upward. Bilateral cavernous sinus invasion can be seen.

Table 1. Endocrine function in a boy during the course of the treatment

\begin{tabular}{lccccc}
\hline & $\begin{array}{c}\text { Before the first } \\
\text { operation } \\
\text { (8 years-old) }\end{array}$ & $\begin{array}{c}\text { After the first } \\
\text { operation }\end{array}$ & $\begin{array}{c}\text { Bc+Oct s.c. } \\
(10 \text { years-old })\end{array}$ & $\begin{array}{c}\text { Bc+Oct LAR (20 mg) } \\
(12.3 \text { years-old })\end{array}$ & $\begin{array}{c}\text { Oct-LAR (20 mg) } \\
+ \text { Cabergoline } \\
(0.25 \text { mg twice a month) } \\
(15-y e a r s-o l d)\end{array}$ \\
\hline Basal GH (ng/ml) & 51.0 & 21.5 & $11.3^{*}$ & $3.5^{*}$ & $0.35^{*}$ \\
IGF-I $(\mathrm{ng} / \mathrm{ml})$ & 1057 & 915 & 755 & 322 & 242 \\
PRL $(\mathrm{ng} / \mathrm{ml})$ & 263.4 & 48.6 & 2.5 & 1.5 & 2.1 \\
\hline
\end{tabular}

Bc, bromocriptine, Oct, octreotide. * GH, nadir values by OGTT. IGF-1 levels (-1.96SD to +1.96SD) for normal Japanese boy. Age 910 years old, 87 to $405 \mathrm{ng} / \mathrm{ml}$, Age 11-13, 115 to $545 \mathrm{ng} / \mathrm{ml}$. Age 15-17, 287 to $555 \mathrm{ng} / \mathrm{ml}$.

not GH (Table 1). Subcutaneous injection of $100 \mu \mathrm{g}$ octreotide frequently caused nausea and gradually led to the patient's poor compliance. Therefore, the therapy was changed to monthly injections of octreotide-LAR (10 mg.i.m.) at the age of 12.3 years. As no side effect of octreotide-LAR was seen, the dose of octreotideLAR was increased to $20 \mathrm{mg}$. After 1 year treatment, the nadir GH value by OGTT was $3.5 \mathrm{ng} / \mathrm{ml}$, and IGF-1 decreased to $322 \mathrm{ng} / \mathrm{ml}(115-545 \mathrm{ng} / \mathrm{ml},-1.96 \mathrm{SD}$ to $+1.96 \mathrm{SD}$ for normal Japanese boy between 1113 years old) (Table 1). OGTT examination showed normal glucose tolerance and ultrasonographic examination did not show gallstones. His puberty gradually progressed. However, as defect of left visual field worsen due to progressive left optic canal stenosis again, he underwent second neurological decompression of the left optic nerve at 13.4 years of age. After surgery, in addition to octreotide-LAR $(20 \mathrm{mg})$, cabergoline $(0.25 \mathrm{mg}$ twice a month) was started. The nadir GH value by OGTT was $0.35 \mathrm{ng} / \mathrm{ml}$, and serum IGF-1 was suppressed to $242 \mathrm{ng} / \mathrm{ml}(287-555 \mathrm{ng} / \mathrm{ml}$,
$-1.96 \mathrm{SD} \pm 1.96 \mathrm{SD}$ for normal Japanese boy between 15-17 years old). In Fig. 1, his adult height was $178 \mathrm{~cm}(+2.5 \mathrm{SD}$ for normal Japanese boy) at the age of 15.7 years. During this regimen, the size of the pituitary adenoma remained unchanged and the fibrous dysplasia of skull region has not progressed.

OGTT showed impaired glucose tolerance with fasting capillary blood glucose $87 \mathrm{mg} / \mathrm{dl}$ and a $120 \mathrm{~min}$ value of $224 \mathrm{mg} / \mathrm{dl}$. Gallstones were also identified. The dose of octreotide-LAR has been reduced to $10 \mathrm{mg}$ and the dose of cabergoline has been increased $(0.25 \mathrm{mg}$ once a week) since then and have been followed-up.

\section{Discussion}

Our patient was diagnosed as MAS and pituitary gigantism by GH and PRL-secreting pituitary adenoma at the age of 8 years despite rapid linear growth from 3 years of age. GH excess is present in $20 \%$ of the pa- 
tients with MAS [5, 6]. GH excess in MAS worsens morbidity related fibrous dysplasia in the craniofacial bones and this condition is a risk for hearing loss or blindness $[5,7,8]$. Therefore, GH secretion in patients with MAS must be evaluated.

Treatment of patients of MAS with GH excess is difficult because skull involvement frequently prevents neurosurgical excision and because radiotherapy may possibly cause bone sarcomatous transformation [1315]. As medical treatment, octreotide and octreotideLAR have been used with varying degrees of success, but experience in pediatric age is rare [9-11]. In recent years, cabergoline has been used, while the combination of cabergoline and octreotide-LAR can be effective in patients in whom monotherapy with either cabergoline or octreotide alone was unsuccessful. Akintoye et al. [5] reported medical treatment of GH excess in MAS patients. In 6 of the 7 patients treated with cabergoline, serum IGF-1 concentrations decreased, but not to the normal range. Further in this study, octreotide-LAR treatment (dose was 20 to 40 $\mathrm{mg}$ ) normalized IGF-1 in 4 of 8 patients. The remaining 4 patients were treated with a combination of cabergoline and octreotide-LAR and showed an additive effect. Two patients who treated with the combination of cabergoline and octreotide-LAR were children (12 and 14 years-old). Schoof et al. [12] reported a 13 year-old boy of MAS and gigantism. They also used octreotide-LAR for one year and it was partially effective for the patient. In our patient, octreotide-LAR appeared to be partially effective; however, it could not prevent the stenosis of optic canal due to fibrous dysplasia. Therefore, cabergoline was added. This combination successfully suppressed serum GH and IGF-1 levels, but impaired glucose tolerance and gallstones probably due to octreotide-LAR were observed after 3-year treatment. Studies of octreotide-LAR to acromegaly in adulthood demonstrated that several patients developed gallstones and impairment of glucose tolerance [16-18]. In two previous reports of treatment of GH excess in MAS, no adverse event due to octreotide-LAR was reported $[5,12]$. Three-year duration of octreotide-LAR is likely to cause side effects in our patient.

Recently, two studies of patients with MAS showed that pegvisomant therapy was effective $[15,19]$. Further, successful treatment of 12-year-old pituitary gigantism by pegvisomant has been reported [20]. Thus, the other option would be pegvisomant in our patient.

Fibrous dysplasia in MAS can cause fracture and deformity in affected bones like our patient. His affected bone legions are spread in all bones. Recently, a number of uncontrolled studies of bisphosphonate therapy for fibrous dysplasia have been reported [21-23]. This regimen appears to be well tolerated and be useful to reduce bone pain; however, reduction or arrest in size of fibrous dysplasia lesions is difficult. Glorieux and Rauch [23] have thus suggested that relief of bone pain is the first indication for this treatment at present.

We report a Japanese MAS boy with GH excess. The therapy of octreotide-LAR and cabergoline was effective, but adverse events by octreotide-LAR occurred. To assess long-term effect of newly developed medical treatment in children, further accumulation of pediatric patients with MAS and GH excess is necessary.

\section{References}

1. Weinstein LS, Shenker A, Gejman PV, Merino MJ, Friedman E, Speigel AM (1991) Activating mutations of the stimulatory $\mathrm{G}$ protein in McCune-Albright syndrome. $N$ Engl J Med 325: 1688-1695.

2. Weinstein LS, Yu S, Warner DR, Liu J (2001) Endocrine manifestations of stimulatory $G$ protein alphasubunit mutations and the role of genomic imprinting. Endocr Rev 22: 675-705.

3. Volkl TMK, Dorr HG (2006) McCune-Albright syndrome: clinical picture and natural history in children and adolescents. J Pediatr Endocrinol Metab Suppl 19: 551-559.

4. Bhansali A, Sharma BS, Sreenivasulu P, Singh P,
Vashisth RK, Dash RJ (2003) Acromegaly with fibrous dysplasia: McCune-Albright Syndrome - clinical studies in 3 cases and brief review of literature - Endocr J 50: 793-799.

5. Akintoye SO, Chebli C, Booher S, Feuillan P, Kushner $\mathrm{H}$, Leroith D, Cherman N, Bianco P, Wientroub S, Robey PG, Collins MT (2002) Characterization of gspmediated growth hormone excess in the context of McCune-Albright syndrome. J Clin Endocrinol Metab 87: 5104-5112.

6. Christoforidis A, Maniadaki I, Stanhope R (2006) McCune-Albright syndrome: growth hormone and prolactin hypersecretion. J Pediatr Endocrinol Metab 
Suppl 2: 623-625. Review.

7. Cuttler L, Jackson JA, Saeed uz-Zafar M, Levitsky LL, Mellinger RC, Frohman LA (1989) Hypersecretion of growth hormone and prolactine in McCune-Albright syndrome. J Clin Endrocrinol Metab 68: 1148-1154.

8. Uwaifo GI, Robey PG, Akintoye SO, Collins MT (2001) Clinical picture: fuel on the fire. Lancet 357: 2011.

9. Sherman SI, Ladenson PW (1992) Octreotide therapy of growth hormone excess in the McCune-Albright syndrome. J Endocrinol Invest 15: 185-190.

10. Chanson P, Dib A, Visot A, Derome PJ (1994) McCune-Albright syndrome and acromegaly: clinical studies and responses to treatment in five cases. Eur $J$ Endocrinol 31: 229-234.

11. Feuillan PP, Jones J, Ross JL (1995) Growth hormone hypersecretion in a girl with McCune-Albright syndrome: comparison with controls and response to a dose of long-acting somatostatin analog. J Clin Endocrinol Metab 80: 1357-1360.

12. Schoof E, Dorr HG, Kiess W, Ludecke DK, Freitag E, Zindel V, Rascher W, Dotsch J (2004) Five-year follow-up of a 13-year-old boy with a pituitary adenoma causing gigantism-effect of octreotide therapy. Horm Res 61: 184-189.

13. Ruggieri P, Sim FH, Bond JR, Unni KK (1994) Malignancies in fibrous dysplasia. Cancer 73: 1411-1424.

14. Hansen MR, Moffat JC (2003) Osteosarcoma of the skull base after radiation therapy in a patient with McCune-Albright syndrome: Case report. Skull Base 13: 79-83.

15. Galland F, Kamenicky P, Affres H, Reznik Y, Pontvert D, Le Bouc Y, Young J, Chanson P (2006) McCuneAlbright syndrome and acromegaly: effects of hypothalamopituitary radiotherapy and/or pegvisomant in somatostatin analog-resistant patients. J Clin Endocrinol Metab 91: 4957-4961.

16. Akintoye SO, Kelly MH, Brillante B, Cherman N, Turner S, Butman JA, Robey PG, Collins MT (2006) Pegvisomant for the treatment of gsp-mediated growth hormone excess in patients with McCune-Albright syndrome. J Clin Endocrinol Metab 291: 2960-2966.

17. Oshino S, Saitoh Y, Kasayama S, Arita N, Ohnishi T, Kohara H, Izumoto S, Yoshimine T (2006) Short-term preoperative octreotide treatment of GH-secreting pituitary adenoma: predictors of tumor shrinkage. Endocr J 53: 125-132.

18. Cozzi R, Montini M, Attanasio R, Albizzi M, Lasio G, Lodrini S, Doneda P, Cortesi L, Pagani G (2006) Primary treatment of acromegaly with octreotide LAR: a long-term (up to nine years) prospective study of its efficacy in the control of disease activity and tumor shrinkage. J Clin Endocrinol Metab 91: 1397-1403.

19. Bevan JS, Atkin SL, Atkinson AB, Bouloux PM, Hanna F, Harris PE, James RA, McConnell M, Roberts GA, Scanlon MF, Stewart PM, Teasdale E, Turner HE, Wass JA, Wardlaw JM (2002) Primary medical therapy for acromegaly: an open, prospective, multicenter study of the effects of subcutaneous and intramuscular slow-release octreotide on growth hormone, insulinlike growth factor-I, and tumor size. J Clin Endocrinol Metab 87: 4554-4563.

20. Lauberg MRP, Hoejberg AS, Brock-Jacobsen B (2006) Pegvisomant therapy in pituitary gigantism: successful treatment in 12-year-old girl. Eur J Endocrinol 153: 195-201.

21. Chan B, Zacharin M (2006) Pamidronate treatment of polyostotic fibrous dysplasia: failure to prevent expansion of dysplastic lesions during childhood. $J$ Pediatric Endocrinol Metab 19: 75-80.

22. Lala R, Matarazzo P, Andreo M, Marzari D, Bellone J, Corrias A, de Sanctis C; Study Group for Gs alpha Protein Related Diseases of the Italian Society for Pediatric Endocrinology and Diabetes (2006) Bisphosphonate treatment of bone fibrous dysplasia in McCuneAlbright syndrome. J Pediatric Endocrinol Metab suppl 2: $583-593$.

23. Glorieux FH, Rauch F (2006) Medical therapy of children with fibrous dysplasia. J Bone Miner Res Suppl 2: $110-113$. 